\title{
Organic-Inorganic Artificial Ion Channel Polyvinylidene Fluoride Membranes for Controllable Selectivity Transport of Alkali Metal Cations
}

\author{
Ye Tian ${ }^{1,2}$, Shaohua Jin ${ }^{1}$, Xinxin Zhang ${ }^{3}$, Lihua Wang ${ }^{3, *}$, Yakai Lin ${ }^{2,4}, *$, Yutao Jin ${ }^{2}$ and \\ Lijie Li ${ }^{1, *}$ \\ 1 School of Material Science and Engineering, Beijing Institute of Technology, Beijing 100081, China; \\ tian.ye@scinormem.com (Y.T.); jinshaohua@bit.edu.cn (S.J.) \\ 2 Beijing Scinor Membrane Technology Co. Ltd., Beijing 100083, China; jinyutao@tsinghua.edu.cn \\ 3 Key Laboratory of Green Printing, Institute of Chemistry, Chinese Academy of Science, Beijing 100190, \\ China; zhangxinxin8758@163.com \\ 4 Beijing Key Laboratory of Membrane Materials and Engineering, Department of Chemical Engineering, \\ Tsinghua University, Beijing 100084, China \\ * Correspondence: wanglh@iccas.ac.cn (L.W.); yk_lin@tsinghua.edu.cn (Y.L.); lilijie2003@bit.edu.cn (L.L.)
}

Received: 14 July 2020; Accepted: 28 July 2020; Published: 31 July 2020

\begin{abstract}
In this article, organic-inorganic hybrid materials with different functional groups were used to form organic-inorganic hybrid dense membranes for selective separation of mono/divalent ions by blending these materials and polyvinylidene fluoride (PVDF) in dimethylacetamide with $\mathrm{HCl}$ as the catalyst. The membranes prepared by 3-(ureido benzene) propyltriethoxysilane (H1), 3-(ureido-4-methoxyphenyl) propyltriethoxysilane (H2), 3-(ureido-3-chloro-4-methoxyphenyl) propyltriethoxysilane (H3), 3-(ureidoindazolyl) propyltrieth-oxysilane (H4), or 3-(ureidopentanol) propyltriethoxysilane (H5) were labeled as HM1-HM5, respectively. The transport properties of different chlorides were tested. The effects of different anions on sodium cation transport were also tested. The results showed that $\mathrm{HM} 1-\mathrm{HM} 4$ could transport monovalent $\mathrm{Li}^{+}, \mathrm{Na}^{+}$, and $\mathrm{K}^{+}$except $\mathrm{Ca}^{2+}$ and $\mathrm{Mg}^{2+}$, and the permeability of $\mathrm{Li}^{+}, \mathrm{Na}^{+}$, and $\mathrm{K}^{+}$through the hybrid membranes followed the order of $P_{\mathrm{Na}+}>P_{\mathrm{K}+}>P_{\mathrm{Li}+}$. Moreover, membranes with different $\mathrm{H} 2$ content were also prepared due to HM2 having the best ion transport performance. The ion transport performance increased accordingly with the mass ratio of $\mathrm{H} 2$ to PVDF, and the permeability of $\mathrm{Na}^{+}$was twice that of $\mathrm{Li}^{+}$and $\mathrm{K}^{+}$when the mass ratio was $15 / 10$. Under this condition, it was also proved that $\mathrm{NH}_{4}{ }^{+}$could not transport through the hybrid membrane with various selectivity for different anions as $\mathrm{Cl}^{-}>\mathrm{NO}_{3}{ }^{-}>\mathrm{HCO}_{3}{ }^{-}>\mathrm{SO}_{4}{ }^{2-}$.
\end{abstract}

Keywords: artificial ion channel membrane; organic-inorganic; selectivity transport; dialysis

\section{Introduction}

Artificial ion channel membranes, similar to those in living organisms in function, have attracted increasing attention due to their potential application in the fields of chemistry, biology, and materials science. Over the past decade, crown-ethers [1-4], cyclic peptides [5], and calixarene have been extensively investigated for the development of ion channel membranes through self-assembly and self-organization [6-8]. However, due to the complex synthesis steps of supramolecular compounds such as crown-ethers, the conditions for the assembly of these compounds into ion channels are harsh, so they are not suitable for amplification applications. Therefore, it is very important to research and develop new artificial ion channel membranes with ion transport function.

On this basis, hybrid organic-inorganic materials offer another promising approach to designing nanostructured materials with tailored chemical and physical properties [9]. A kind of hybrid 
material which is represented by bridged silsesquioxanes with a wide variety of tunable properties, where the organic fragment is covalently linked to the silicate framework [10] is highly attractive. In organic-inorganic complex membranes, alkali cations $\left(\mathrm{K}^{+}\right.$and $\left.\mathrm{Na}^{+}\right)$can diffuse along cation- $\pi$ aromatic conduction formed in the ureidoareneheteropolysiloxane hybrids by combining the main organic aryl bridging substructure with the urea groups [11]. However, the performance of hybrid organic-inorganic membranes, that is, ion permeability and selectivity, is restricted to monovalent alkali cations, and the controllable selectivity transport of the cations was not studied [12,13]. In addition, the effect of their corresponding anions on the transport is seldom taken into consideration. Moreover, the hybrid membranes reported so far are almost constituted on a supporting layer with a multi-layer structure, complicating the research on the transport mechanism.

In this work, a simple blending method of preparation of organic-inorganic complex membranes was proposed. Polyvinylidene fluoride (PVDF) has excellent mechanical properties, high chemical resistance, good thermal stability, and excellent film-forming ability, and is widely used to separate membrane materials [14-17]. In this article, five organic-inorganic hybrid materials were used to form organic-inorganic hybrid dense membranes for selective separation of mono/divalent ions by blending these materials and polyvinylidene fluoride (PVDF) in dimethylacetamide with $\mathrm{HCl}$ as the catalyst. These materials were 3-(ureido benzene) propyltriethoxysilane (H1), 3-(ureido-4-methoxyphenyl) propyltriethoxysilane (H2), 3-(ureido-3-chloro-4-methoxyphenyl) propyltriethoxysilane (H3), 3-(ureidoindazolyl) propyltrieth- oxysilane (H4) and 3-(ureidopentanol) propyltriethoxysilane (H5), and the membranes prepared by them were labeled as HM1-HM5, respectively. The transport properties of different chlorides $\left(\mathrm{LiCl}, \mathrm{NaCl}, \mathrm{KCl}, \mathrm{NH}_{4} \mathrm{Cl}\right.$, and $\mathrm{CaCl}_{2}$ ) were tested. The effects of different anions on sodium cation transport were also tested. Moreover, membranes (named M1, M2, and M3) with the different $\mathrm{H} 2$ contents were prepared, and the influences of the content of organic-inorganic hybrid materials on the membrane properties were also studied.

\section{Materials and Methods}

\subsection{Reagents and Materials}

Polyvinylidene fluoride (PVDF): Solef 6010, Solvay; N, N-dimethylacetamide (DMAc) and hydrochloric acid ( $\mathrm{HCl})$ : analytical purity (AR), Chemical Reagent Co., Ltd. of China Pharmaceutical Group, Beijing, China, the rest of the reagents were also analytical purity (AR).

Hybrid materials (H1-H5) were provided by the laboratory of new materials, Institute of Chemistry, Chinese Academy of Sciences, and were prepared from 3-isocyanatopropyltriethoxysilane and aniline with different functional groups, as shown in Figure 1.

H1:
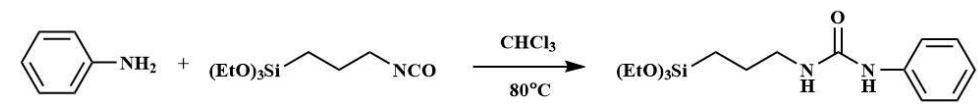

H2:
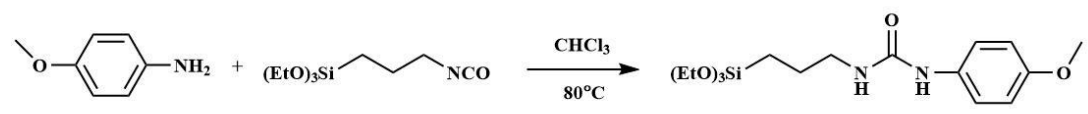

H3:
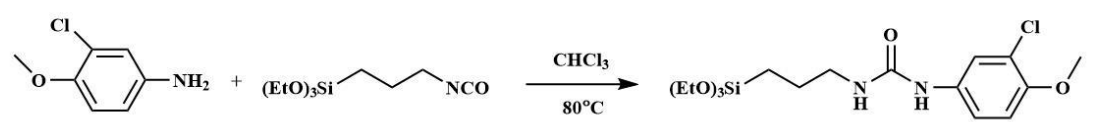

H4:
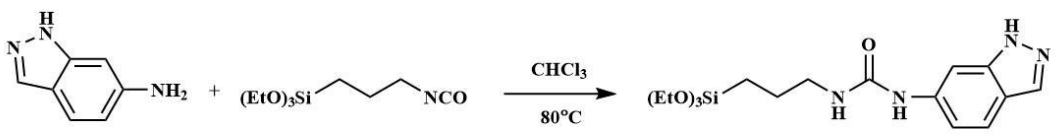

H5:

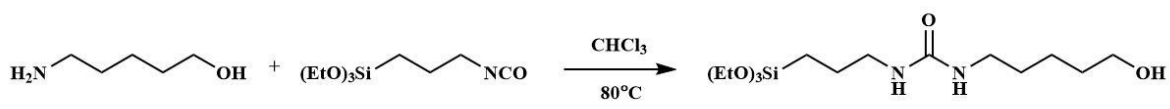

Figure 1. Synthesis of $\mathrm{H} 1-\mathrm{H} 5$. 


\subsection{Preparation of Hybrid Membranes with Different Hybrid Organic-Inorganic Materials}

$\mathrm{H} 1-\mathrm{H} 5$ (5\%, $0.5 \mathrm{~g})$ was blended with polyvinylidene fluoride (PVDF) $(15 \%, 1.5 \mathrm{~g})$ in $\mathrm{N}$, N-Dimethylacetamide (DMAC, $8 \mathrm{~g}$ ), and $0.04 \mathrm{~mL}$ of $36 \%-37 \% \mathrm{HCl}$ was added to the blend. The mixed solution was heated and stirred at $100{ }^{\circ} \mathrm{C}$ for $48 \mathrm{~h}$ to obtain a transparent membrane liquid. Then the membrane liquid was ultrasonically cleaned in an ultrasonic cleaner for $15 \mathrm{~min}$, and then left for $48 \mathrm{~h}$ at room temperature. The corresponding hybrid membranes (HM1-HM5) were obtained by coating the solution onto a glass sheet using a spin-coating method, followed by drying under an infrared light for $15 \mathrm{~min}$. For comparison, a membrane without hybrid organic-inorganic materials (M0) was also prepared.

$\mathrm{H} 1-\mathrm{H} 4$ can self-assemble to form regular structures under neutral, acidic, or alkaline conditions, as shown in Figure 2. The $\left(-\mathrm{Si}(\mathrm{OEt})_{3}\right)$ group can be hydrolyzed to form a cross-linked siloxane network (-Si-O-Si(OH)-O-Si-). At the same time, the $\mathrm{N}-\mathrm{H}$ group in the molecular chain and the $\mathrm{O}$ on the urea group in the adjacent molecule can be bonded to each other through intermolecular hydrogen bonding to form an anion transport channel. The aromatic ring in the structure can form an aromatic channel which can transfer cations through the cation- $\pi$ bond [18].

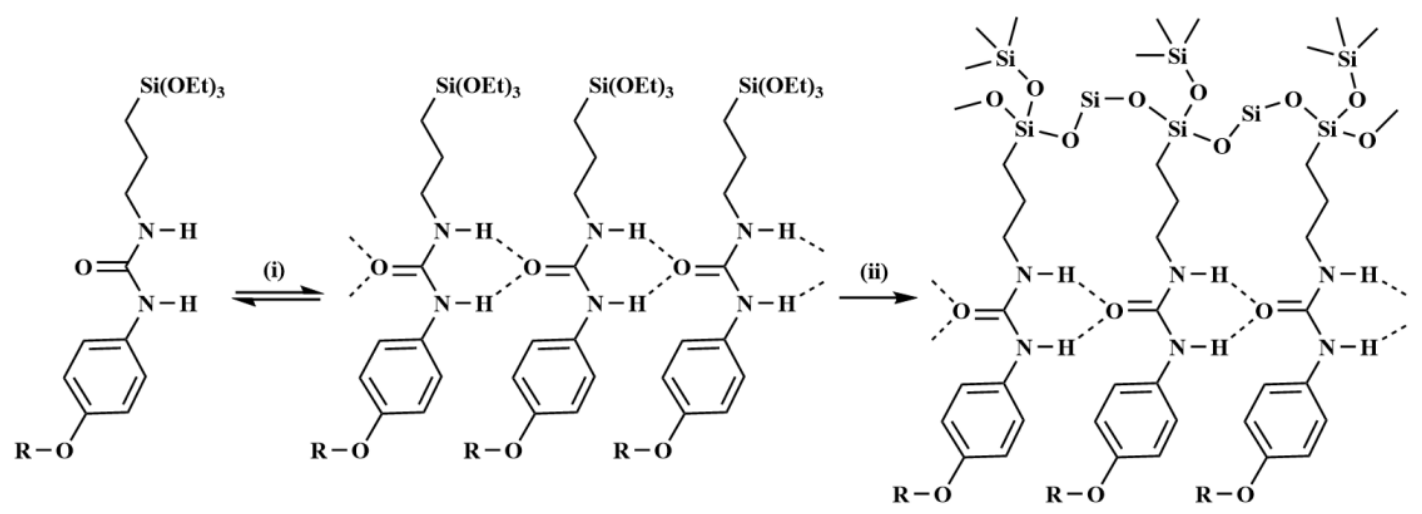

Figure 2. Self-organization process of organic-inorganic hybrid functional materials.

\subsection{Preparation of Hybrid Membranes with Different Ratios of $\mathrm{H} 2$}

By blending $\mathrm{H} 2$ and PVDF in three different mass ratios (1:15, 5:15, and 10:15) in dimethylacetamide with $\mathrm{HCl}$ as the catalyst and heating at $100{ }^{\circ} \mathrm{C}$ for $48 \mathrm{~h}$, a transparent and homogeneous solution was formed. The corresponding hybrid membranes (M1, M2, and M3) were obtained by coating the solution onto a glass sheet using a spin-coating method, followed by drying under an infrared light for $15 \mathrm{~min}$. The proportion of the materials in the membrane solution is shown in Table 1.

Table 1. The proportion of the materials in the membrane solution.

\begin{tabular}{cccc}
\hline Materials & M1 & M2 & M3 \\
\hline PVDF(15\%)/g & 1.5 & 1.5 & 1.5 \\
$\mathrm{DMAC} / \mathrm{g}$ & 8.4 & 8 & 7.5 \\
$\mathrm{H} 2 / \mathrm{g}$ & $0.1(1 \%)$ & $0.5(5 \%)$ & $1(10 \%)$ \\
$\mathrm{HCl} / \mathrm{mL}$ & 0.02 & 0.04 & 0.08 \\
\hline
\end{tabular}

\subsection{Characterization of Hybrid Membranes}

\subsubsection{Observation of the Morphology of the Hybrid Membranes}

The surface and cross-section of the membranes were observed by a scanning electron microscope (SEM, Hitachi S-4800, Tokyo, Japan) with the accelerating voltage set to $1.0 \mathrm{kV}$. The membranes were fractured in liquid nitrogen and coated with platinum for the SEM cross-section structure observation. 
In order to further observe the morphology of the organic-inorganic hybrid ion channel membrane, the thin film samples were prepared by ion thinning technology, and then were directly observed by a transmission electron microscope (TEM, JEOL 2010F, Tokyo, Japan) with the accelerating voltage set to $200 \mathrm{kV}$.

\subsubsection{Dialysis Transport Procedure}

A membrane transport experiment was performed with a bi-compartment device [19]. The device consists of two cells (the volume of each cell is $1 \mathrm{~L}$ ) separated by a solid membrane $\left(\mathrm{S}=0.5024 \mathrm{~cm}^{2}\right)$ with the active dense film facing the feed phase. The feed phase was an aqueous solution containing either $0.3 \mathrm{M} \mathrm{CaCl}_{2}, 0.3 \mathrm{M} \mathrm{MgCl}_{2}$, or $0.3 \mathrm{M} \mathrm{LiCl}+\mathrm{NaCl}+\mathrm{KCl}$ for the cation transport experiments, while the receiving phase contained only deionized water with the same volume. The electrical conductivity and the concentrations of $\mathrm{Li}^{+}, \mathrm{Na}^{+}, \mathrm{K}^{+}$, and $\mathrm{Ca}^{2+}$ were monitored at different time intervals by using a conductivity analyzer and a flame photometer. This experiment was carried out under the static state.

The transport performance of the membranes was also further evaluated by measuring the ionic current across the membranes in the environment with different chloride salts and sodium salts. Ionic current measurement was carried out with a Keithley 6487 picoammeter and custom designed electrolyte cells with the membrane mounted in between. When the measurement was in operation, the same kind of salt solution with the same volume and concentration $(0.1 \mathrm{~mol} / \mathrm{L})$ was in the cells on either side of the membrane and the micro voltage and current were recorded by the picoammeter.

\section{Results and Discussions}

\subsection{Microstructure and Morphology of Hybrid Membranes}

Figures 3 and 4 show the microstructures and morphologies of M0 and HM1-HM5. It can be seen that the surfaces of these membranes are dense without micropores, and the thicknesses of the membranes are about 30-48 $\mu \mathrm{m}$. Moreover, there is a dendrite crystal structure on the surface of $\mathrm{M} 0$, but the membrane surface is dense without micropores, and the film thickness is $32.5 \mu \mathrm{m}$. Two kinds of structures can be observed on the surfaces of HM1-HM4: one is the dendritic crystal structure, and the other is the smooth discontinuous elliptical structure. The elliptical structure is self-organically formed in the sol-gel process of organic-inorganic hybrid ion channel in the functional material H1-H4, which is consistent with the cross-section structure of (b), (c), (d), and (e) in Figure 4. The surface structure of HM5 is smooth and dense, which is quite different from that of the HM1-HM4 membranes. This is due to the existence of a linear pentanol group in the structure of functional material H5, which has good compatibility with PVDF, and there is no obvious two-phase structure when the two materials are mixed into the membrane.

As shown in Figure 5, scanning electron microscopy (SEM) reveals that the membranes are dense without micro pinholes. Figures $3 \mathrm{a}$ and $4 \mathrm{a}$ depict the surface and the cross-section of PVDF blank membrane M0 and show a well-resolved bulk crystalline area at nanometric scale. With the addition of $\mathrm{H} 2$, some oval-shaped domains from $\mathrm{H} 2$ were clearly observed in the matrix, as shown in Figure 5a for M1. With the further increase of $\mathrm{H} 2$ content in the membrane, the domains from $\mathrm{H} 2$ spread and made contact with each other to form a smooth oval-shaped structured membrane, which can also be observed in the cross-section images of M1, M2, and M3 (Figure 5d-f), as compared to that of the M0. 

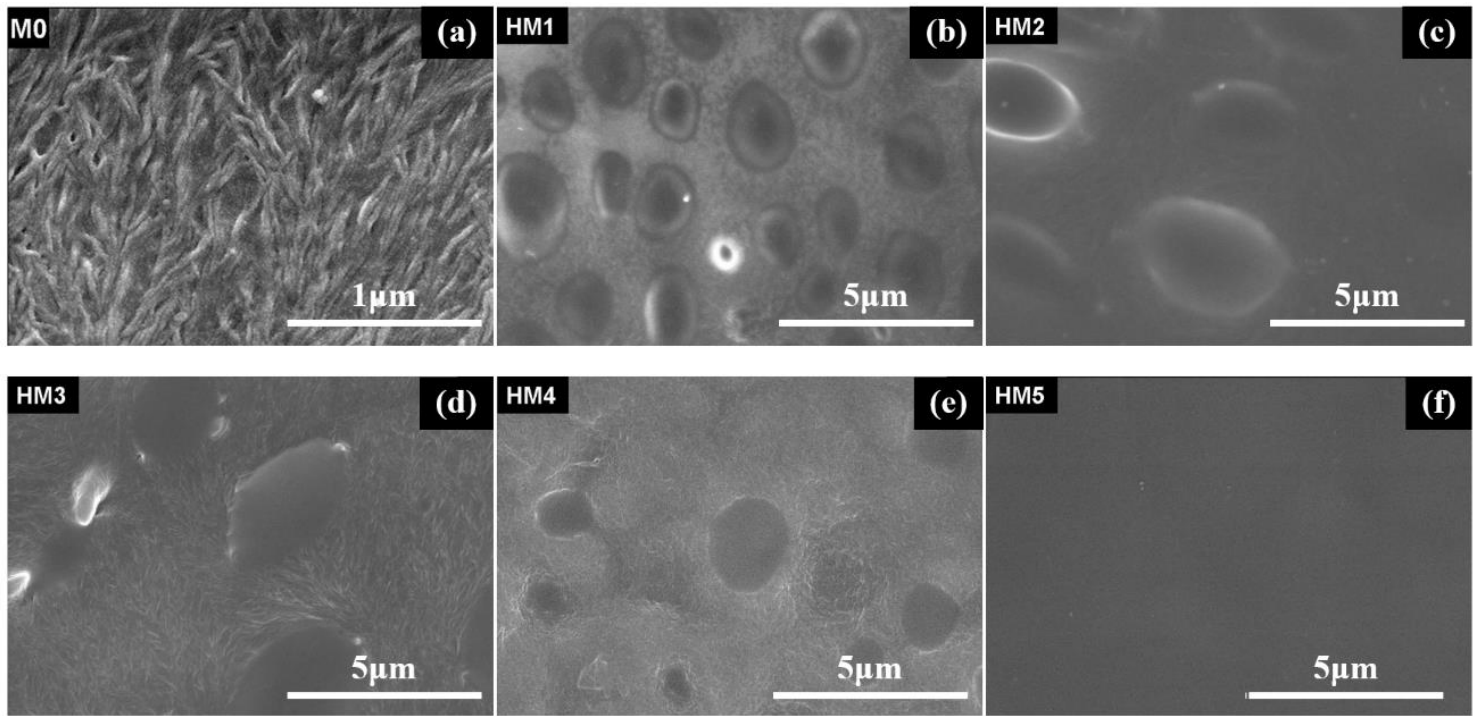

Figure 3. SEM images of the surfaces of the blank membrane and organic-inorganic hybrid ion channel membranes: (a) M0; (b) HM1; (c) HM2; (d) HM3; (e) HM4; (f) HM5.
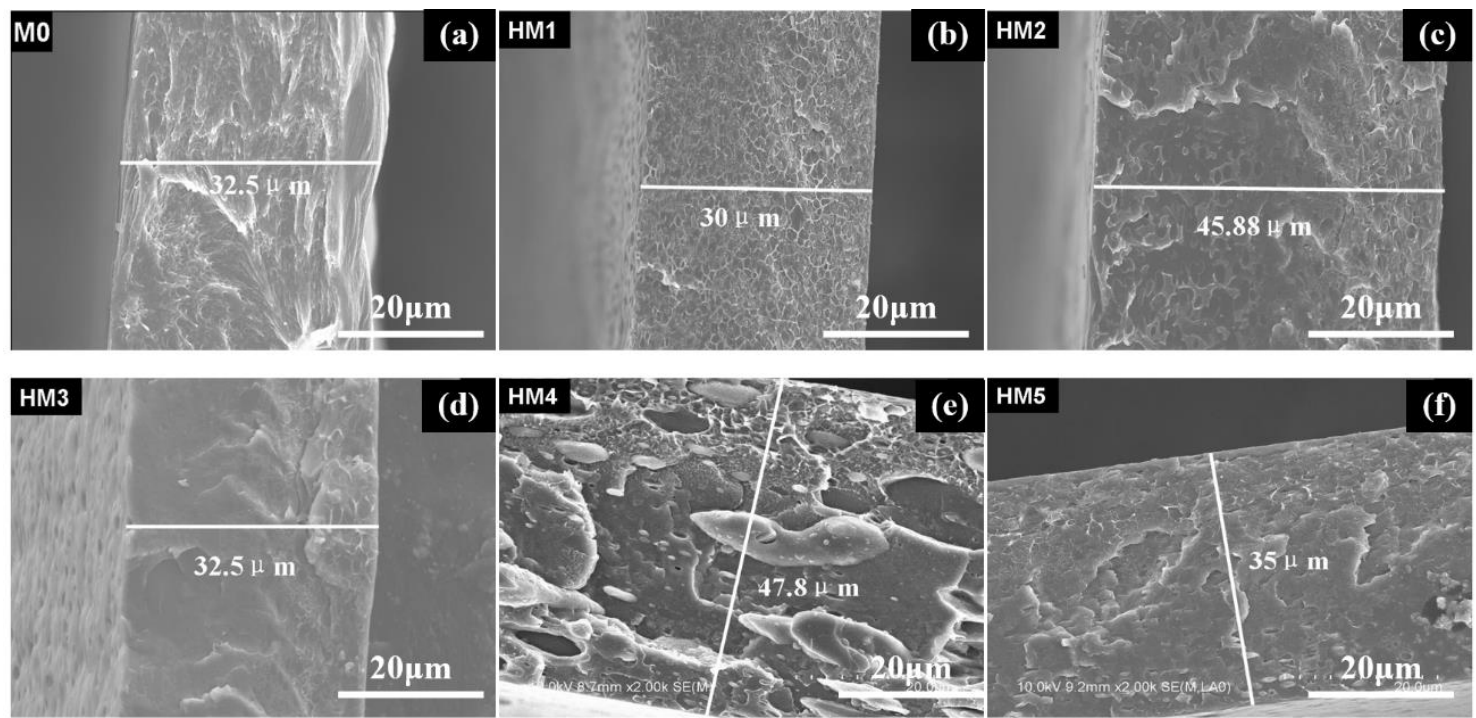

Figure 4. SEM images of the cross-sections of the blank membrane and organic-inorganic hybrid ion channel membranes: (a) M0; (b) HM1; (c) HM2; (d) HM3; (e) HM4; (f) HM5.

Figure 6a depicts a typical TEM image of an M3 membrane and shows well-resolved and highly ordered uniform rows. The repeating motif is formed by discrete alternative light (inorganic siloxane matrix) and dark (organic self-assembled molecules) rows. The periodicity of parallel sheets of the self-organized organic and siloxane inorganic networks are observed in the crystal packing (Figure 6b), which is consistent with the structure observed in the TEM. 

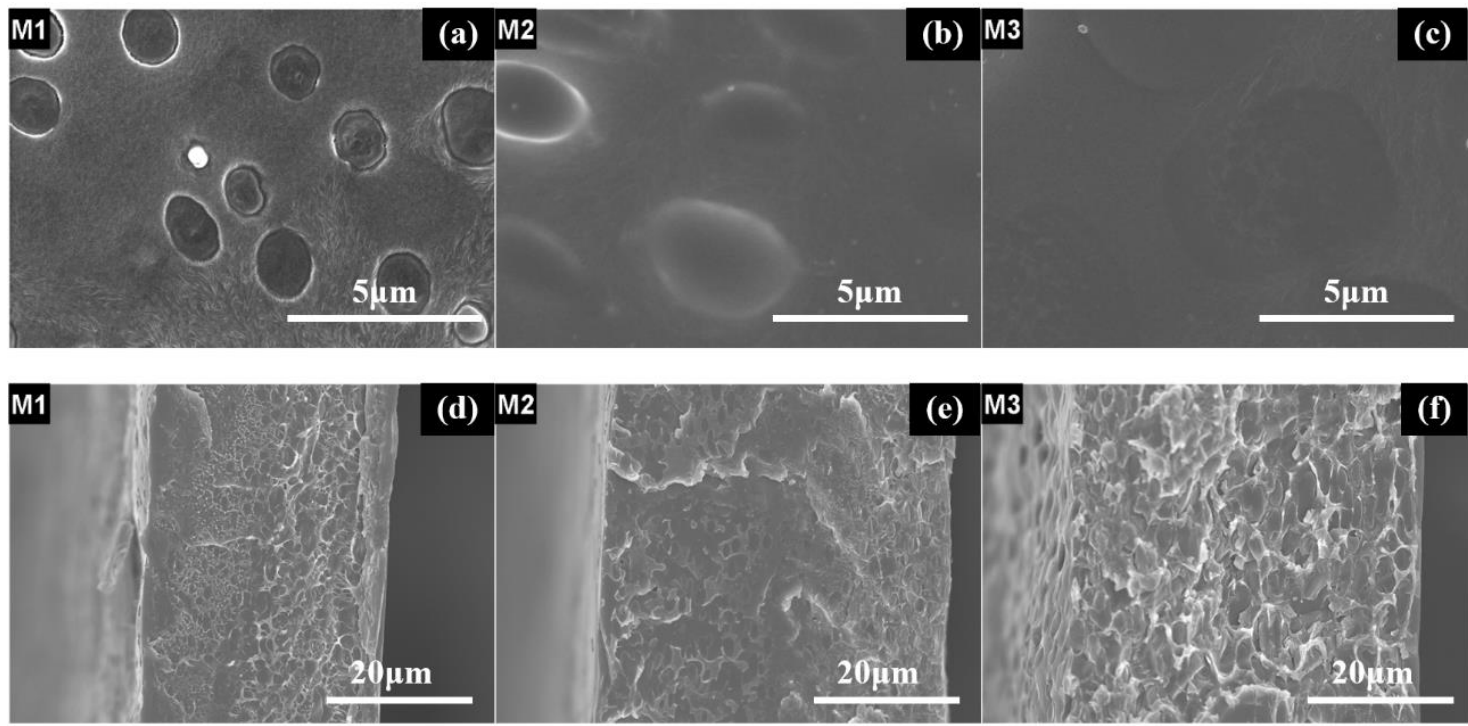

Figure 5. SEM images of the surfaces of M1 (a), M2 (b), M3 (c), and the cross-sections of M1 (d), M2 (e), M3 (f).

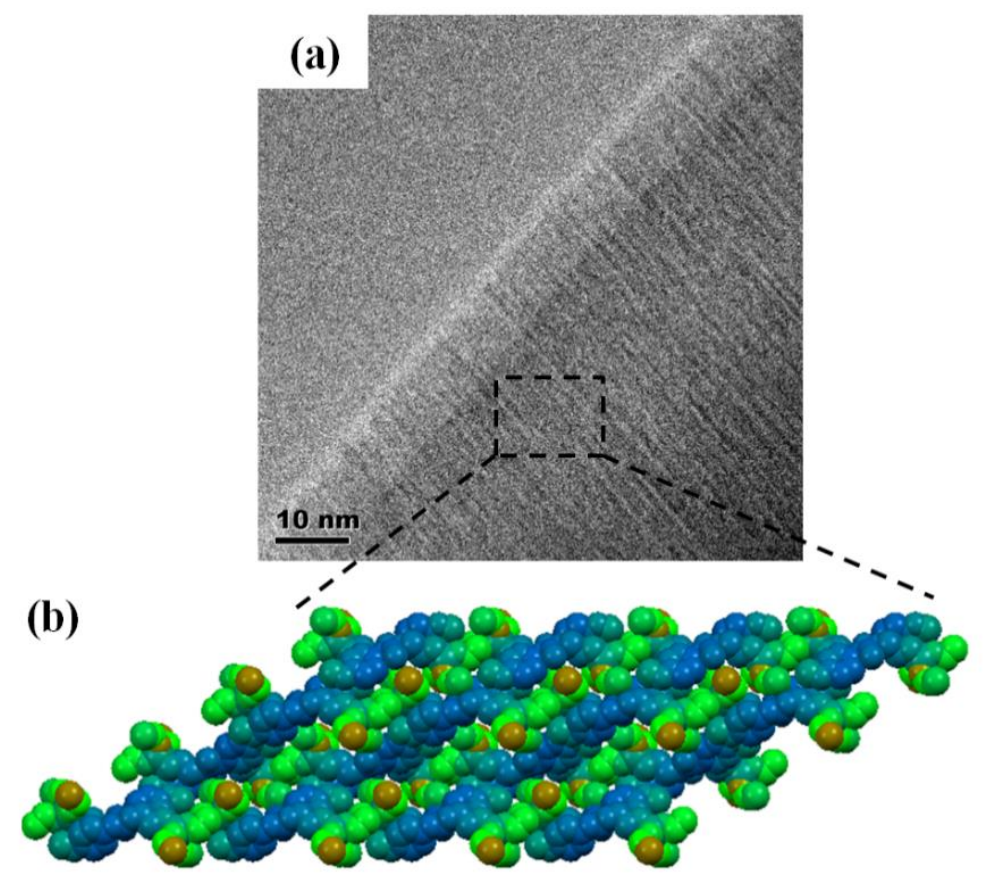

Figure 6. Progressive nanoscale self-organization of the hybrid membrane: (a) TEM image of the hybrid membrane M3; (b) the crystal packing of compound $\mathrm{H} 2$.

\subsection{Dialysis of the Transport Properties of the Membranes}

Figure 7 shows the time-dependent curve of the conductivity of $\mathrm{Li}^{+}, \mathrm{Na}^{+}$, and $\mathrm{K}^{+}$. It can be seen from Figure $7 \mathrm{a}$ that the conductivity of M0 remains basically unchanged, indicating that PVDF has no transport performance for $\mathrm{Li}^{+}, \mathrm{Na}^{+}$, and $\mathrm{K}^{+}$. The electrical conductivity of HM1, HM2, and HM4 increased rapidly, and the conductivity increased by about $1000 \mu \mathrm{s} / \mathrm{cm}$ within $70 \mathrm{~h}$. The conductivity of HM3 and HM5 increased slowly, only increasing by about $200-500 \mu \mathrm{s} / \mathrm{cm}$ at $70 \mathrm{~h}$. The experimental results show that the organic-inorganic hybrid ion channel functional materials HM1-HM5 have certain transport properties for $\mathrm{Li}^{+}, \mathrm{Na}^{+}$, and $\mathrm{K}^{+}$, and among $\mathrm{H} 1-\mathrm{H} 5, \mathrm{H} 2$ has the best ion transport performance. 
Figure $7 \mathrm{~b}$ shows the permeability values of $\mathrm{Li}^{+}, \mathrm{Na}^{+}$, and $\mathrm{K}^{+}$of $\mathrm{HM} 1-\mathrm{HM} 5$, which were calculated through the reported method $[19,20]$. It can be seen that the permeability of $\mathrm{Li}^{+}, \mathrm{Na}^{+}$, and $\mathrm{K}^{+}$in HM1, HM2, and HM3 is $P_{\mathrm{Na}+}>P_{\mathrm{K}+}>P_{\mathrm{Li}+}$. The permeability of $\mathrm{Li}^{+}, \mathrm{Na}^{+}$, and $\mathrm{K}^{+}$in $\mathrm{HM} 4$ is $P_{\mathrm{Na}+} \approx P_{\mathrm{K}+}>P_{\mathrm{Li}+}$, and that of HM5 is $P_{\mathrm{K}+}>P_{\mathrm{Na}+} \approx P_{\mathrm{Li}+}$. In addition, it also can be seen from Figure $7 \mathrm{~b}$ that the permeability of $\mathrm{Li}^{+}, \mathrm{Na}^{+}$, and $\mathrm{K}^{+}$of $\mathrm{HM} 2$ is much higher than that of the other four membranes $(\mathrm{H} 2>\mathrm{H} 1>\mathrm{H} 4>\mathrm{H} 3>\mathrm{H} 5)$.

The aromatic ring in the structure of $\mathrm{H} 1-\mathrm{H} 4$ can form an aromatic channel which can transfer cations through the cation- $\pi$ bond. Therefore, the ionic transport properties depend on the cation- $\pi$ interaction between cations and benzene or heterocycles. The electron donating group can strengthen the cation- $\pi$ force, while the electron withdrawing group will weaken the cation- $\pi$ force. In $\mathrm{H} 2$, the methoxy $\left(-\mathrm{OCH}_{3}\right)$ on the para substituent of the benzene ring is an electron donating group, which can increase the cation- $\pi$ interaction between $\mathrm{Li}^{+}, \mathrm{Na}^{+}$, and $\mathrm{K}^{+}$and the benzene ring, thus promoting the ion transport of the HM2 membrane. In H3, the chlorine group (-CL) on the substituent of the benzene ring is an electron withdrawing group, and its electronegativity is greater than that of methoxy $\left(-\mathrm{OCH}_{3}\right)$ on the para substituent. Therefore, the substituent on the benzene ring acts as an electron withdrawing group, which inhibits the ion transport of HM3. In $\mathrm{H} 4$, although the two adjacent $\mathrm{N}$ heteroatoms on the indazole group make the induced electron absorption capacity of the group a bit larger and inhibit the ion transport of HM4, the electron absorption ability of H4 is still weaker than that of H3, resulting in better ion transport performance in HM4 than in HM3. In H1, there is no substituent in the benzene ring, so the ion transport capacity of HM1 is less than that of HM2, but higher than that of HM3 and HM4. It also can be seen that HM5 has the worst transport performance for $\mathrm{Li}^{+}, \mathrm{Na}^{+}$, and $\mathrm{K}^{+}$, which indicates that the pentanol group in the straight chain has no effect on ion transport.

(a)

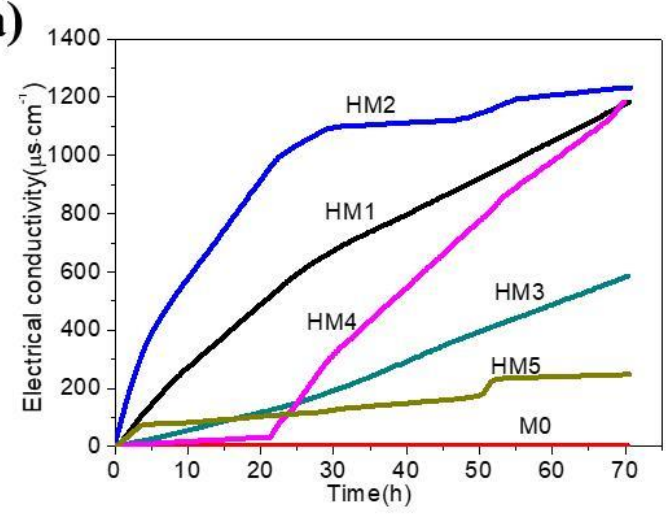

(b)

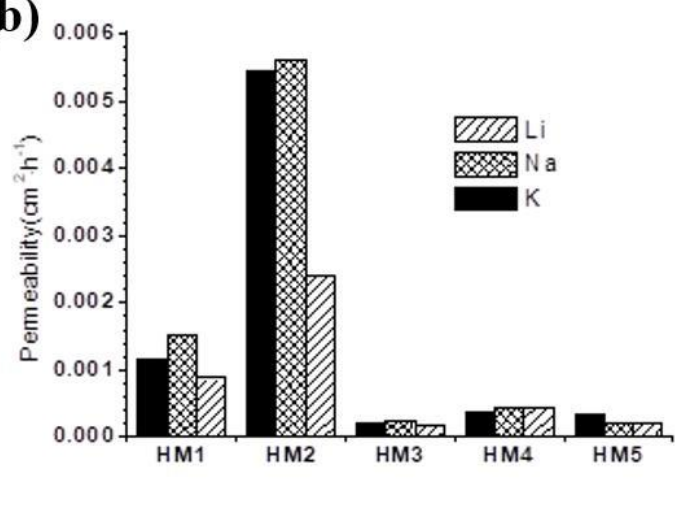

Figure 7. (a) Electrical conductivity of $\mathrm{Li}+, \mathrm{Na}+$, and $\mathrm{K}+$ in $\mathrm{M} 0$ and $\mathrm{HM} 1-\mathrm{HM} 5$; (b) permeability values of $\mathrm{Li}+, \mathrm{Na}+$, and $\mathrm{K}+$ cations in HM1-HM5.

Figure 8 shows the curve of conductivity of $\mathrm{Ca}^{2+}$ and $\mathrm{Mg}^{2+}$ with time. It can be seen from Figure 8 that the conductivity of $\mathrm{Ca}^{2+}$ and $\mathrm{Mg}^{2+}$ of $\mathrm{M} 0, \mathrm{HM} 1$, and HM4 remains unchanged, while the conductivity of HM2, HM3, and HM5 increases, but the conductivity only increases about $10 \mu \mathrm{s} / \mathrm{cm}$ in $50 \mathrm{~h}$, which can be ignored. The results show that PVDF and HM1-HM5 have no transport properties for $\mathrm{Ca}^{2+}$ and $\mathrm{Mg}^{2+}$.

Figure 9a shows the conductance change of $\mathrm{M} 0, \mathrm{M} 1, \mathrm{M} 2$, and $\mathrm{M} 3$ with time for $\mathrm{Li}^{+}, \mathrm{Na}^{+}, \mathrm{K}^{+}$, and $\mathrm{Ca}^{2+}$. With the addition of $\mathrm{H} 2$, the conductance increases for all the cations with increasing the content of $\mathrm{H} 2$ in the membranes and presents a similar increasing trend. Thus, transport behavior was significantly dependent on the ratio of $\mathrm{H} 2$ and PVDF in the membranes. Conductance for $\mathrm{Ca}^{2+}$ was near zero with $\mathrm{M} 2$, despite the fact that the high conductance was measured for $\mathrm{Li}^{+}, \mathrm{Na}^{+}$, and $\mathrm{K}^{+}$ with it. Those results proved that $\mathrm{H} 2$ could transport $\mathrm{Li}^{+}, \mathrm{Na}^{+}$, and $\mathrm{K}^{+}$, but was not selective for $\mathrm{Ca}^{2+}$. The permeabilities of $\mathrm{Li}^{+}, \mathrm{Na}^{+}$, and $\mathrm{K}^{+}$followed the order $P_{\mathrm{Na}+}>P_{\mathrm{K}+}>P_{\mathrm{Li}+}$ and were amplified when the content of $\mathrm{H} 2$ increased in the membrane (Figure 9b). However, there was little difference 
among the permeabilities of $\mathrm{Li}^{+}, \mathrm{Na}^{+}$, and $\mathrm{K}^{+}$in both $\mathrm{M} 1$ and $\mathrm{M} 2$. When the ratio of $\mathrm{H} 2$ and PVDF increased to 10:15 in M3, the difference was remarkably enlarged, as shown in Figure $9 b$, and the permeabilities of $\mathrm{Na}^{+}$was twice more than that of $\mathrm{Li}^{+}$or $\mathrm{K}^{+}$. The results revealed that $\mathrm{H} 2$ is well selected for $\mathrm{Na}^{+}$transport. Usually, $\mathrm{Li}^{+}, \mathrm{Na}^{+}$, and $\mathrm{K}^{+}$transport through the membranes in the forms of hydrated cations, and hydrated ionic radii follow the order $\mathrm{Li}\left(\mathrm{H}_{2} \mathrm{O}\right)_{\mathrm{n}}{ }^{+}>\mathrm{Na}\left(\mathrm{H}_{2} \mathrm{O}\right)_{n}{ }^{+}>\mathrm{K}\left(\mathrm{H}_{2} \mathrm{O}\right)_{n}{ }^{+}$, that is, $\mathrm{Li}\left(\mathrm{H}_{2} \mathrm{O}\right)_{\mathrm{n}}{ }^{+}$is disadvantaged in membrane transport.
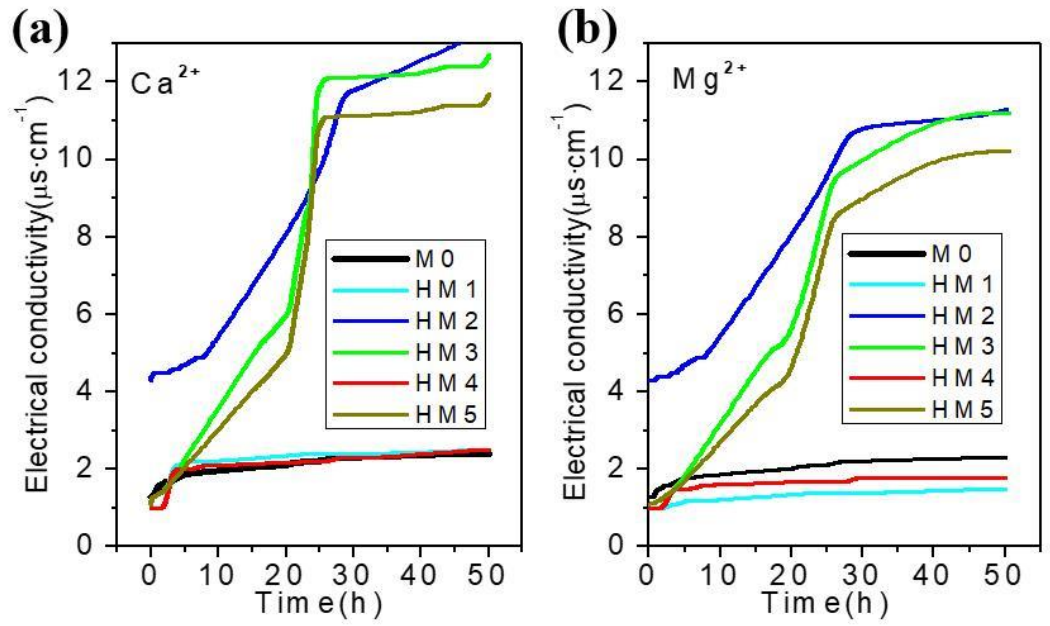

Figure 8. Electrical conductivity of $\mathrm{Ca}^{2+}(\mathbf{a})$ and $\mathrm{Mg}^{2+}$ (b) in blank membrane (M0) and organic-inorganic hybrid ion channel membranes (HM1-HM5) as a function of time.

(a)

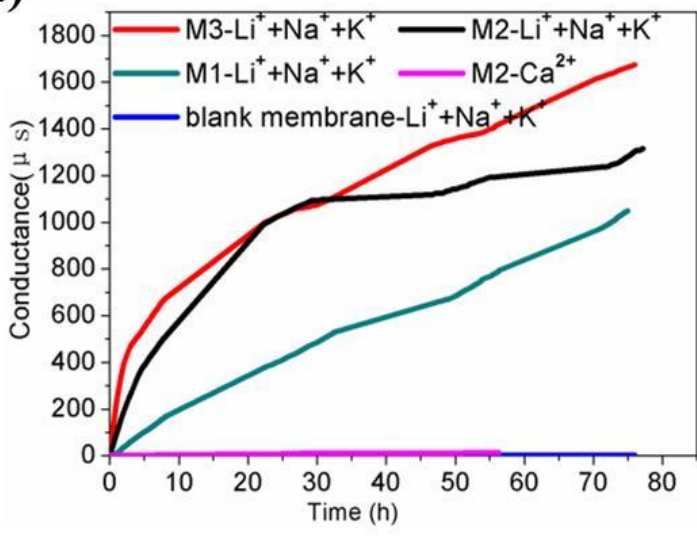

(b)

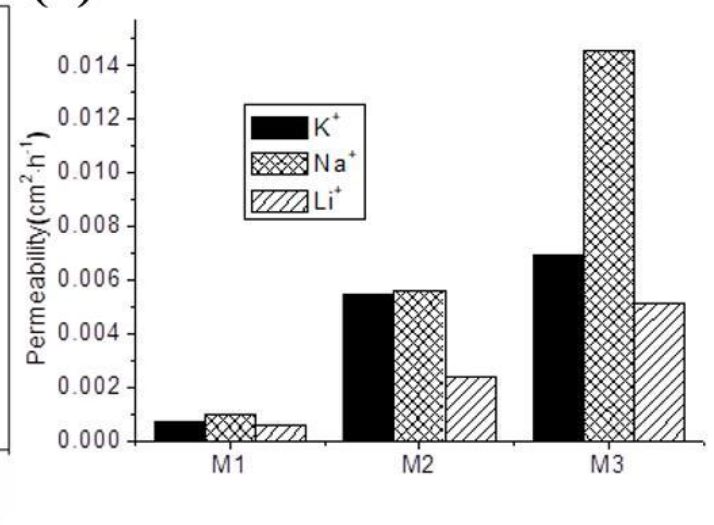

Figure 9. (a) Conductance profiles in the strip phase as a function of time; (b) permeability values of $\mathrm{Li}^{+}, \mathrm{Na}^{+}$, and $\mathrm{K}^{+}$cations in the M1, M2, and M3 hybrid membranes.

A substantial contribution to $\mathrm{Na}^{+}$transport selectivity through $\mathrm{M} 3$ is due to the interaction of the hydrated cations with the hydrophilic methoxyphenyl pathway (Figure 10). The benzene ring could effectively compete with water in the solvation sphere of $\mathrm{K}^{+}$leading to the formation of mixed $\mathrm{K}^{+} / \mathrm{Ar}_{\mathrm{x}} /\left(\mathrm{H}_{2} \mathrm{O}\right)_{\mathrm{y}}$ clusters, which means that partially dehydrated $\mathrm{K}^{+}$may stick within the methoxyphenyl pathway of the membrane [9]. It has been proven that $\mathrm{K}^{+}$interacts with the phenyl in an aqueous solution whereas $\mathrm{Na}^{+}$cation does not $[21,22]$. Therefore, the stronger interaction of $\mathrm{Na}^{+}$ with water prevents cation dehydration, and thus $\mathrm{Na}^{+}$cation is selectively transported as hydration species $\mathrm{Na}\left(\mathrm{H}_{2} \mathrm{O}\right)_{n}{ }^{+}$through the hydrophilic pathways of $\mathrm{M} 3$. 


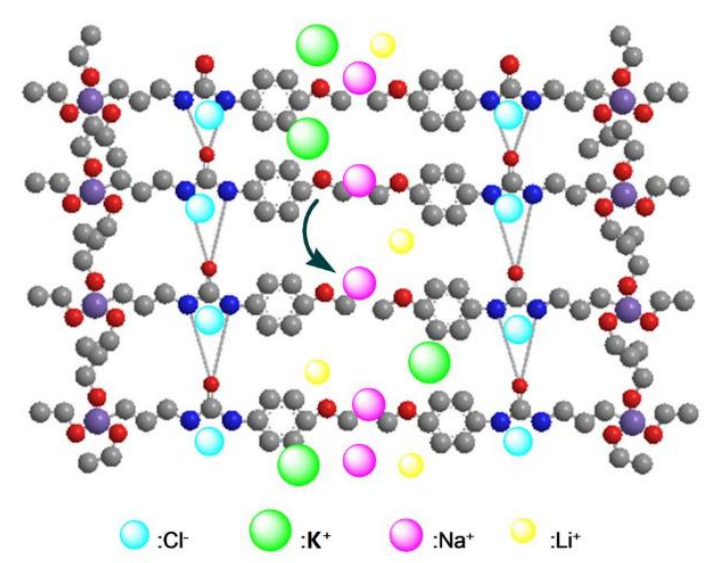

Figure 10. Aromatic cation- $\pi$ and urea anion conduction pathways.

The transport performance of M3 was evaluated by measuring the ionic current across the membrane in an environment with different chloride salts and sodium salts. Ionic current measurement was carried out with a Keithley 6487 picoammeter in a custom designed electrolyte cell with the membrane mounted in between. Figure 11 shows current-voltage (I-V) curves of M3. Figure 11a compares the transmembrane currents of the monovalent salts of $\mathrm{NaCl}, \mathrm{KCl}, \mathrm{LiCl}$, and $\mathrm{NH}_{4} \mathrm{Cl}$. The currents of $\mathrm{NaCl}, \mathrm{KCl}$, and $\mathrm{LiCl}$ kept an increasing trend with increasing the applied voltages, and the current of $\mathrm{NaCl}$ was the highest among them, consistent with the conductance measured above. From Figure 11a, it is clear that the current of $\mathrm{NH}_{4} \mathrm{Cl}$ kept near zero with the applied voltages, indicating that $\mathrm{M} 3$ cannot transport $\mathrm{NH}_{4}{ }^{+}$. For further investigation of anion effect on the transport, a series of sodium salts $\left(\mathrm{NaCl}, \mathrm{NaNO}_{3}, \mathrm{NaHCO}_{3}\right.$, and $\left.\mathrm{Na}_{2} \mathrm{SO}_{4}\right)$ were selected to measure the ionic currents. As shown in Figure 11b, the chloride passed through the membrane faster than the nitrate, bicarbonate or sulfate. This result can be explained due to the migration rates of the anions. When the sodium salts have an equal number of moles, the migration rates of anions follow the order $\mathrm{Cl}^{-}>\mathrm{NO}_{3}{ }^{-}>\mathrm{HCO}_{3}{ }^{-}>\mathrm{SO}_{4}{ }^{2-}$. The membrane has double channels, and can transport ion pairs. The transport rates of cations and anions would influence each other, and the selectivity for $\mathrm{Na}^{+}$ strongly relates to the type of the anions.

(a)

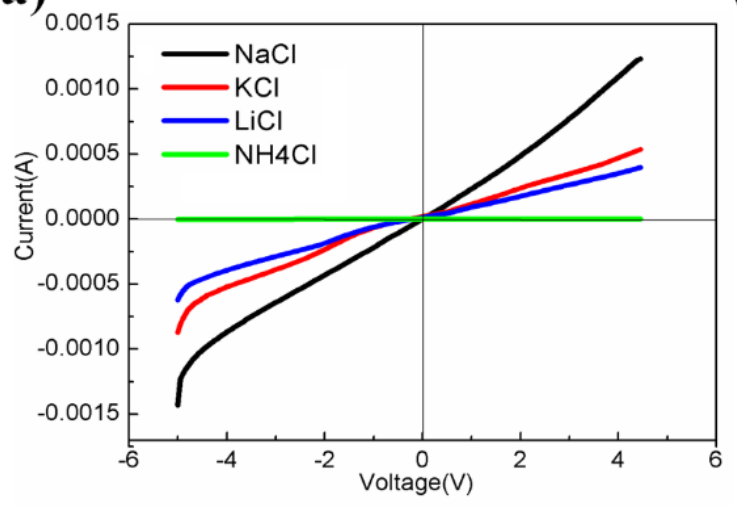

(b)

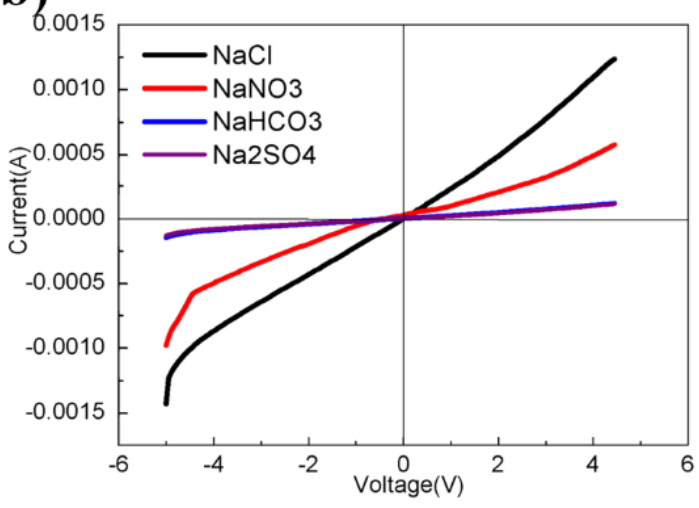

Figure 11. Current-voltage properties of membrane M3: (a) different transported cations with the same anion $\mathrm{Cl}^{-}$, (b) different transported anions with the same cation $\mathrm{Na}^{+}$.

\section{Conclusions}

In this article, $\mathrm{H} 1-\mathrm{H} 5$ organic-inorganic hybrid materials were used to form organic-inorganic hybrid dense membranes. The aromatic ring in the structure of $\mathrm{H} 1-\mathrm{H} 4$ can form an aromatic channel which can transfer cations through the cation- $\pi$ bond. $\mathrm{In} \mathrm{H} 2$, the methoxy $\left(-\mathrm{OCH}_{3}\right)$ on the para 
substituent of the benzene ring is an electron donating group, which can increase the cation- $\pi$ interaction between $\mathrm{Li}^{+}, \mathrm{Na}^{+}$, and $\mathrm{K}^{+}$and the benzene ring, thus promoting the ion transport performance of the HM2 membrane. With the increase of $\mathrm{H} 2$, the ion transport performance of the hybrid membrane increased accordingly. When the mass ratio of $\mathrm{H} 2$ to PVDF was 15:10 (M3), the permeability of $\mathrm{Na}^{+}$ was twice than that of $\mathrm{Li}^{+}$and $\mathrm{K}^{+}$, which showed a good selectivity for $\mathrm{Na}^{+}$. The results of I-V curves showed that $\mathrm{NH}_{4}{ }^{+}$could not transport through M3 and M3 had various selectivity for different anions, such as $\mathrm{Cl}^{-}>\mathrm{NO}_{3}{ }^{-}>\mathrm{HCO}_{3}{ }^{-}>\mathrm{SO}_{4}{ }^{2-}$, suggesting that $\mathrm{M} 3$ was well selected for $\mathrm{Cl}^{-}$. The hybrid membranes could find application in the softening of hard water, the desalination of sea water, ion selection electrodes, biosensors, and other fields.

Author Contributions: Methodology, X.Z., L.W.; investigation, Y.T., S.J.; resources, supervision and project administration. L.W., Y.L., L.L., S.J.; data curation, Y.T., X.Z., Y.J. writing-original draft preparation, Y.T., Y.J.; writing-review and editing, Y.T., S.J. All authors have read and agreed to the published version of the manuscript.

Funding: This research was funded by National Science Foundation of China, grant number 20704041.

Conflicts of Interest: The authors declare that they have no conflict of interest.

\section{References}

1. Beginn, U.; Zipp, G.; Möller, M. Functional Membranes Containing Ion-Selective Matrix-Fixed Supramolecular Channels. Adv. Mater. 2000, 12, 510-513. [CrossRef]

2. Gillers, A.; Barboiu, M. Highly Selective Artificial K+ Channels: An Example of Selectivity-Induced Transmembrane Potential. J. Am. Chem. Soc. 2016, 138, 426-432. [CrossRef]

3. Acar, E.T.; Buchsbaum, S.F.; Combs, C.; Fornasiero, F.; Siwy, Z.S. Biomimetic potassium-selective nanopores. Sci. Adv. 2019, 5, eaav2568. [CrossRef] [PubMed]

4. Fang, A.; Kroenlein, K.; Riccardi, D.; Smolyanitsky, A. Highly mechanosensitive ion channels from graphene-embedded crown ethers. Nat. Mater. 2019, 18, 76-81. [CrossRef]

5. Bong, D.T.; Clark, T.D.; Granja, J.R.; Ghadiri, M.R. Self-Assembling Organic Nanotubes. Angew. Chem. Int. Ed. Engl. 2001, 40, 998-1011. [CrossRef]

6. Sidorov, V.; Kotch, F.W.; Abdrakhmanova, G.; Mizani, R.; Fettinger, J.C.; Davis, J.T. Ion channel formation from a calix[4]arene amide that binds HCl. J. Am. Chem. Soc. 2002, 124, 2267-2278. [CrossRef] [PubMed]

7. Ying, Y.L.; Zhang, J.J.; Meng, F.N.; Cao, C.; Yao, Y.Y.; Willner, I.; Tian, H.; Long, Y.T. A Stimuli-responsive nanopore based on a photoresponsive host-Guest system. Sci. Rep. 2013, 3, 1662. [CrossRef]

8. Bayrakci, M.; Yigiter, S. Synthesis of tetra-substituted calix [4] arene ionophores and their recognition studies toward toxic arsenate anions. Tetrahedron 2013, 69, 3218-3224. [CrossRef]

9. Moreau, J.J.E.; Vellutini, L.; Man, M.W.C.; Bied, C. Shape-controlled bridged silsesquioxanes: Hollow tubes and spheres. Chem. Eur. J. 2003, 9, 1594-1599. [CrossRef]

10. Moreau, J.J.E.; Vellutini, L.; Man, M.W.C.; Bied, C.; Dieudonné, P.; Bantignies, J.L.; Sauvajol, J.L. Lamellar bridged silsesquioxanes: Self-assembly through a combination of hydrogen bonding and hydrophobic interactions. Chem. Eur. J. 2005, 11, 1527-1537. [CrossRef]

11. Michau, M.; Caraballo, R.; Arnal-Hérault, C.; Barboiu, M. Alkali cation- $\pi$ aromatic conduction pathways in self-organized hybrid membranes. J. Membr. Sci. 2008, 321, 22-30. [CrossRef]

12. Hariprasad, R.; Vinothkannan, M.; Kim, A.R.; Yoo, D.J. SPVdF-HFP/SGO nanohybrid proton exchange membrane for the applications of direct methanol fuel cells. J. Dispers. Sci. Technol. 2019, 1-13. [CrossRef]

13. Kim, A.R.; Gabunada, J.C.; Yoo, D.J. Sulfonated fluorinated block copolymer containing naphthalene unit/sulfonated polyvinylidene-co-hexafluoropropylene/functionalized silicon dioxide ternary composite membrane for low-humidity fuel cell applications. Colloid Polym. Sci. 2018, 296, 1891-1903. [CrossRef]

14. Tian, Y.; Jin, S.; Jin, Y.; Ma, W.; Lin, Y.; Li, L. Preparation of polyvinylidene fluoride/modified attapulgite composite ultrafiltration membrane. Polym. Adv. Technol. 2020, 1-7. [CrossRef]

15. Wang, D.L.; Li, K.; Teo, W.K. Preparation and characterization of polyvinylidene fluoride (PVDF) hollow fiber membranes. J. Membr. Sci. 1999, 163, 211-220. [CrossRef]

16. Gu, M.H.; Zhang, J.; Wang, X.L.; Tao, H.J.; Ge, L.T. Formation of poly(vinylidene fluoride) (PVDF) membranes via thermally induced phase separation. Desalination 2006, 192, 160-167. [CrossRef] 
17. Cui, Z.Y.; Tang, X.X.; Li, W.; Liu, H.N.; Zhang, J.; Wang, H.; Li, J.X. EVOH in situ fibrillation and its effect of strengthening, toughening and hydrophilic modification on PVDF hollow fiber microfiltration membrane via TIPS process. J. Membr. Sci. 2019, 54, 5971-5987. [CrossRef]

18. Wang, L.H.; Zhang, X.X.; Yun, Y.B. Preparation of hybrid ion channel membrane for recognizing and transporting sodium ion. Desalin. Water Treat. 2011, 34, 234-238. [CrossRef]

19. Nasr, G.; Barboiu, M.; Ono, T.; Fujii, S.; Lehn, J.M. Dynamic polymer membranes displaying tunable transport properties on constitutional exchange. J. Membr. Sci. 2008, 321, 8-14. [CrossRef]

20. Zhang, X.X.; Wang, L.H.; Yun, Y.B. Construction of Self-Organized Hybrid Ion Channel Membrane and Cationic Transport Mechanism. Acta Chim. Sin. 2012, 70, 170-176. [CrossRef]

21. Cabarcos, O.M.; Weinheimer, C.J.; Lisy, J.M. Competitive solvation of $\mathrm{K}+$ by benzene and water: Cation- $\pi$ interactions and $\pi$-hydrogen bonds. J. Chem. Phys. 1998, 108, 5151-5154. [CrossRef]

22. Cabarcos, O.M.; Weinheimer, C.J.; Lisy, J.M. Size selectivity by cation- $\pi$ interactions: Solvation of K+ and $\mathrm{Na}+$ by benzene and water. J. Chem. Phys. 1999, 110, 8429-8435. [CrossRef]

(C) 2020 by the authors. Licensee MDPI, Basel, Switzerland. This article is an open access article distributed under the terms and conditions of the Creative Commons Attribution (CC BY) license (http://creativecommons.org/licenses/by/4.0/). 